\title{
The Impermanence of Art and Beauty
}

\author{
By Laura E. Osterweis*
}

Using lipstick as my medium, my work deals with the impermanence of art and beauty. I created the series, "Can't You Put on a Little Lipstick?" from an enormous collection of lipsticks I amassed over a number of years. But that's not the whole story... my grandmother has always gently urged, " Can't you put on a little lipstick?" This repeated suggestion, combined with my lipstick collection, started me thinking about how wearing lipstick contributes to our concepts of beauty. Is everything more beautiful with lipstick? Questions about the endurance of my art emphasize the impermanence my medium and content. Exploring concepts of beauty and graphic expression, I crop subject matter to encourage the viewer to closely think about parts of subjects we do not often consciously examine. Working with a bright palette, I investigate how repurposed material adds to my message. Examples of my work can be viewed at www.thelipstickartist.com.

\section{Introduction}

I created the series, "Can't You Put on a Little Lipstick?" from an enormous collection of giveaway lipsticks I amassed over a number of years.

But that is not the whole story ... since I was of dating age my grandmother has always gently urged, " Can't you put on a little lipstick?" This repeated suggestion, combined with my lipstick collection, started me thinking about how wearing lipstick contributes to our concepts of beauty. Is everything more beautiful with lipstick? Can lipstick make a frown more attractive? Does it make an old woman prettier? That is what led me to put on a little lipstick, on watercolor paper, to see how it might be perceived.

How perfect to have the opportunity to present my work in Athens where the nature of beauty was first debated by the Ancient Greeks. The question of whether the value of the work is in the eye of the beholder or whether there is a measurable aesthetic value based on the arrangements of parts remains a hotly debated topic still today. ${ }^{1}$ Hopefully my work will challenge you to think about your views on beauty, art and the impermanence of it all as reflected by my medium and as mirrored by the ancient Grecian works of art, now crumbled, cracked and in ruins, around us.

* Associate Professor, Framingham State University, USA.

1. Crispin Sartwell, "Beauty," in The Stanford Encyclopedia of Philosophy, ed. Edward N. Zalta, (2014), http://goo.gl/jvh9S3. 


\section{Why Lipstick?}

In 2009, I enrolled in a course entitled, "Developing Your Own Personal Style" at the Danforth Museum (Framingham, MA, USA). When the instructor, Zach Pelham, asked what I wanted to work on, I thought I would paint seascapes and beach scenes but his expressionless reaction made me realize he had heard this too many times before. Being the teacher pleaser that I am, I mentioned that I had always wanted to create something with my large collection of giveaway lipsticks, his eyes lit up and his enthusiasm inspired me to pursue my idea further. Large department stores offer giveaways with a purchase of a certain amount of their product. I always waited to buy my moisturizer until it was "Bonus Time" so that I could get the freebies, regardless of the fact that the colors were usually not ones I would even wear. But I held onto these giveaway lipsticks with the idea that someday I would do something with all of them. But that is not the whole story ... when I also commented that my grandmother has always suggested "Laura, can't you put on a little lipstick?" in the hopes of helping me attract a mate, Pelham was ecstatic and declared that would be the perfect name for my eventual exhibit.

\section{Concepts of Beauty}

When we think of lipstick we cannot help but think of concepts of beauty, sexuality, and attraction. Women use lipstick to appear prettier, sexier, or in some way different than they are naturally. Using the medium of lipstick brings these thoughts to bear on all of the pieces I create with it. Realizing that the medium would be so tied to the meaning of my artwork I chose to first create a series of lips that would question the medium itself (Figure 1). Is everything more beautiful with lipstick? Can lipstick make a frown more attractive? Does it make an old woman prettier? The piece was accepted into a juried exhibition of the Cambridge Art Association (Cambridge, MA, USA). Upon the success of my first piece, I created a second piece, this time a series of eyes, using only eye makeup, again questioning the medium itself (Figure 1). This piece, accepted into a juried exhibition in the Viridian Artists Inc. Gallery (Chelsea, New York, USA), also explores how iconic images and appropriations created in a medium laden with meaning affects the viewer's perception of the work. 

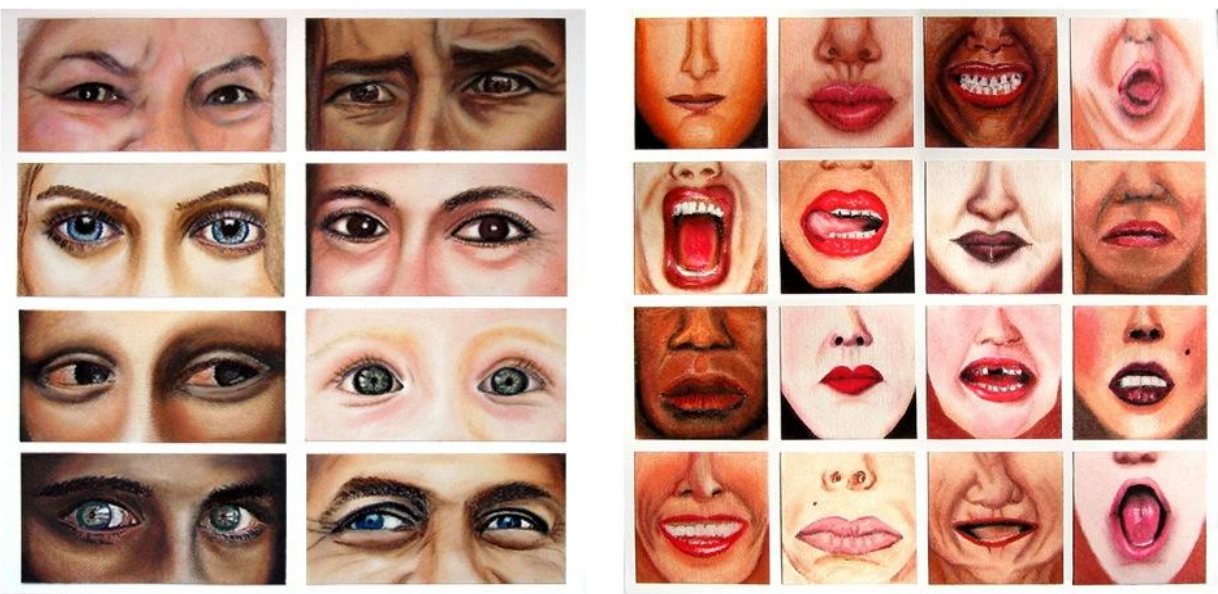

Figure 1. Looking Beautiful and "Can't you put on a little lipstick?"

Though not at all intentional, my artwork exhibits many similarities to Pop-art of the 1960s in my exploration of the medium, appropriation of iconic images, motif of feminine facial features, recycling of materials and use of a vibrant color palette. Interestingly, I also have roots as a graphic designer like two of the most famous pop artists, Andy Warhol and Ed Ruscha, so it is not surprising that my work has developed in a similarly graphic fashion. The inventive method by which Warhol created his famous Campbell's Soup can portraits caused an immediate public reaction as viewers questioned whether the medium (and content) constituted art. In addition, he used the brightly colored iconic image of the everyday grocery store soup can object as his subject. ${ }^{2}$ As Warhol's work confronts the viewer with the question of "what is art?" I am attempting to confront the viewer with "what is beauty?" using both medium and content to deliver my message. Marshall McLuhan, famed for having coined the expression "the medium is the message" in his book, Understanding Media: The Extensions of Man, argued that we should focus on how the medium, as opposed to the content, affects the public's response. ${ }^{3}$ The importance and function of the medium cannot be denied as it was Warhol's unconventional non-painterly style that brought attention and elicited reaction to his subject matter. Likewise, my medium of makeup serves to deliver my message as well.

The repetition in terms of both subject matter and appropriation of some of my work can also be seen as bearing a likeness to Warhol and other pop artists. Consider how replication affects the value, worthiness or beauty of an original piece. For example, we already associate many attributes with the

2. Andy Warhol, "Campbell's Soup Cans" (synthetic polymer paint, New York: Museum of Modern Art, 1962).

3. Marshall McLuhan, Understanding Media: The Extensions of Man (New York: McGraw-Hill, 1964), 8. 
painting of the Mona Lisa: money, fame, mystery and the gaze that follows you around the room. Advertisers might use the Mona Lisa in a "Got Milk" commercial because they know viewers will instantly recognize the face, associate the image with a sense of value, and transfer that association to the product of their milk. "For Picasso, appropriation was not merely an artistic exercise in which ... he explored his relationship to great art and artists. Indeed, the artist perceived appropriation as a magical transference of power ...". Even though the image of the Mona Lisa is re-contextualized, the original associations and power of the Mona Lisa are tied to the appropriated image. "The autonomy of art is linked not just with issues of innovation, but also with the question of the relationship between an artistic tradition and its past". Combining the ideas of money, fame, mystery, and the eyes that follow you around the room, plus additional associations with makeup, which is usually used to enhance natural beauty or cover up imperfections, provides the viewer with much to think about.

\section{Brief History of Lipstick}

Since the medium plays such a role in my work, a brief history of lipstick shows how the perception of a work created with the medium might be different depending on the current attitude toward lipstick.

Coloring lips is hardly a modern fashion. The use of lipstick was documented on ancient Egyptian scrolls found in a five-thousand-year-old Sumerian tomb. In the fourth century B.C., Greek women used seaweed and mulberry to paint their lips. During ovulation and arousal women's lips naturally become fuller and redder and their cheeks flush. Lipstick and rouge mimic this look so it is no surprise that during the Dark and Middle Ages, lip coloring was banned by the Christian church and typically only worn by prostitutes. ${ }^{6}$ Consciously or unconsciously women wear lipstick to appear ready for action. The cosmetic industry prospers on this.

In the sixteenth century, Queen Elizabeth popularized the look of bright red lips and a stark white face. By the eighteenth century, lipstick became popular with middle and lower classes as well. In 1880, Guerlain, a French cosmetic company, was the first to produce a commercial lipstick product. The

4. Timothy Burgard, "Picasso and Appropriation," The Art Bulletin 73, no. 3 (1991): 479.

5. Jeremy Tanner, The invention of art history in Ancient Greece (Cambridge: Cambridge University Press, 2006), 184.

6. Meg Cohen Ragas, Karen Kozlowski, and Veronique Vienne, Read my lips (San Francisco: Chronicle Books [u.a.], 1998), 14. 
rise of photography in the 1920s made lipstick more acceptable and popular. The first swivel tube was invented in $1923{ }^{7}$

Lipstick sales are often seen as an economic indicator. During times of economic crisis, lipstick sales actually increase. During the 1940s lipstick became scarce because the castor oil and petroleum used to produce it were in high demand for the war effort. In the 1970s black lipstick became the signature look of Punk and Goth subcultures. ${ }^{8}$ Chubby sticks are perhaps the newest invention on the lipstick scene but the use of lipstick remains strong with 800-900 million lipsticks being sold every year worldwide. ${ }^{9}$

The meaning of my work can be affected by the current attitude toward lipstick at any given time since, as I have already discussed, it is impossible to evaluate my art without bringing certain associations of lipstick to it. The gendered beliefs about beauty and use of makeup might affect the interpretation of my work as well. Certainly consumers of makeup are typically, but not limited to, women. Conversations that include both beauty and makeup are most often centered on women. The use of lipstick can be seen as either a means of hiding something less than perfect or as a means of revealing a woman to be more confident and powerful. "Lipstick feminism" was coined to express the notion that wearing makeup and embracing femininity actually makes women appear stronger rather than the just the product of forced societal expectations. ${ }^{10}$ Anything created with lipstick then might be open to this same controversy: does the lipstick cover something ugly or expose something beautiful? In 1982, Polish artist Ewa Partum performing naked created red lipstick imprints on white paper while mouthing overtly feminist sentiment. ${ }^{11}$ Unlike Partum, I have no feminist agenda though I can appreciate how one might make associations to feminism when I ask my viewer to think about concepts of beauty. Instead my intention is to get the viewer to think about what makes something beautiful in the manner of Italian philosopher, Umberto Eco, who writes that "in almost all aesthetic theories, at least from ancient Greece to modern times, it has been recognized that any form of ugliness can be redeemed by a faithful and efficacious artistic portrayal". ${ }^{12}$ He suggests that by taking an aged statue and placing it in a well-respected museum it becomes beautiful. Does makeup function in the same way to beautify an object; and what becomes of the work as it ages?

7. Ibid, 18.

8. Ibid, 35.

9. Jean-Yves Bourgeois and Vincent Gallon, "Lipstick: A Safe Bet," Premium Beauty News, 2009, http://goo.gl/csq4ge, (accessed October 16, 2015).

10. Natasha Walter, Living Dolls (London: Virago, 2010), 28 \& 43.

11. Pawel Leszkowicz, "Sex and Subversion in the Art of the People's Republic of Poland," The Central European Journal of Social Sciences and Humanities 20 (2007).

12. Umberto Eco, On ugliness (New York: Rizzoli, 2007), 19. 


\section{My Creative Process}

I usually work from my own photograph or a photo composite that I create in Adobe Photoshop by combining two or more of my photos. I draw a basic sketch of the image in outlines on watercolor paper. After much experimentation with different surfaces, including canvas, board, and sandpaper, I determined that the watercolor paper works best because the dimples on the surface absorb the thick medium while still allowing blending. Initially I painted directly on the watercolor paper. Now I treat the surface of the paper with gesso, a paint mixture that will hopefully help to preserve the watercolor paper surface so that the oils of the lipstick do not eat through the paper.

I consult my lipstick color swatches to select the palette to use for the particular piece, selecting anywhere between 5 to 25 different tubes. I currently have over 75 tubes in my collection. I then apply the lipstick to the paper directly from the tube (Figure 2). Using my finger and a paper towel I further smudge the lipstick marks into the paper. When I need a finer line, I apply lipstick liner or eyeliner and occasionally use cotton swabs and toothpicks to direct the paint. Highlights are tricky because lipstick smudges and is difficult to remove from the paper. I use a sheer lipstick or gloss to fill in the areas I wish to remain lighter. Discovering that museum putty can be used like an eraser to help lift color off the page made a huge difference in my ability to create and control highlights and alter areas that already had been painted with lipstick. I use black lipstick to create shadows.
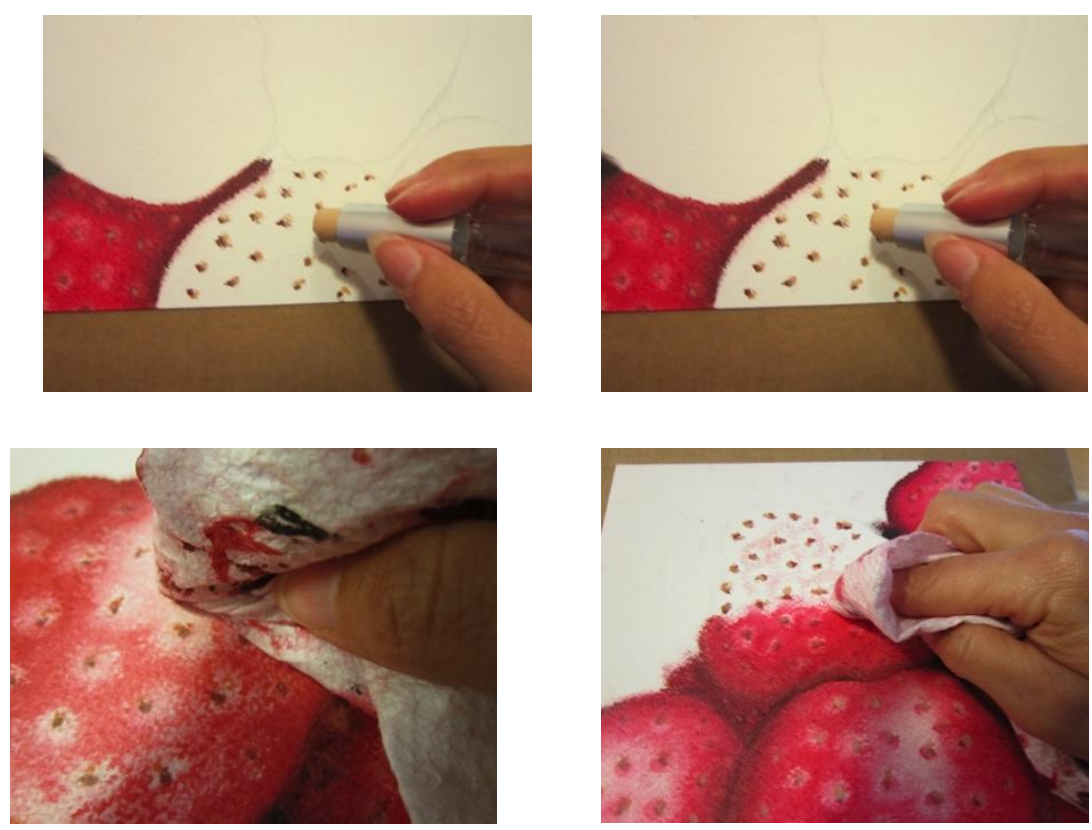

Figure 2. Process 
My notebook of lipstick color swatches and the paper towel used for blending become works of art in and of themselves with their interestingly shaped marks and colors (Figure 3). I make use of the elaborately descriptive names cosmetic companies use to market their tubes of color by naming my completed pieces based on the dominant color I use.

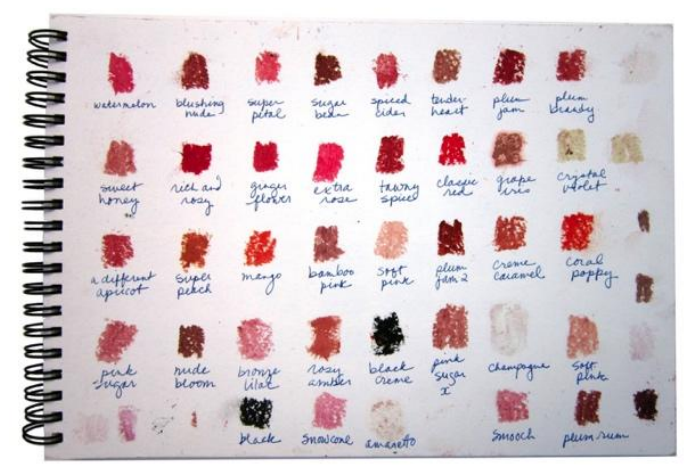

Figure 3. Lipstick Palette

\section{Inspiration}

I crop subject matter to draw particular attention to one specific aspect or feature of my subject and to encourage the viewer to more closely observe and think about parts of subjects that we see regularly but do not often consciously examine (Figure 4). "It is only by selection, by elimination, by emphasis that we get at the real meaning of things", stated Georgia. ${ }^{13}$ I am inspired by her floral pieces in which her tightly cropped subject matter, bright color palettes and abstractions seem to extend far beyond the canvas while offering the viewer a chance to really know something intimately. O'Keeffe's work is often considered somewhat suggestive, an attribute that seems most appropriate to embed in lipstick art. I want my work to leave something to the imagination or interpretation of the viewer.

13. Georgia O'Keeffe, "I Can't Sing So I Paint," New York Sun, December 5, 1922, quoted in O'Keeffe, Stieglitz, and the Critics, 1916-1929, ed. Barbara Buhler Lynes (Chicago: Chicago University Press, 1991), 180. 


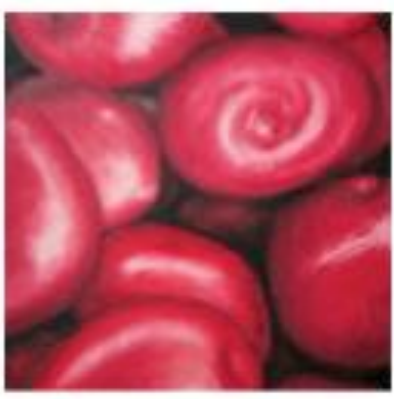

Cherry Red tipstick on wotercolor poper

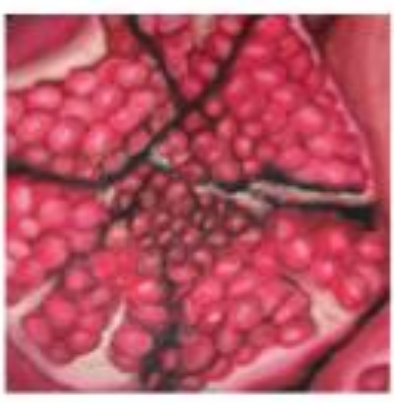

Pomegranate Crush Lpiticx on watecolor pape:

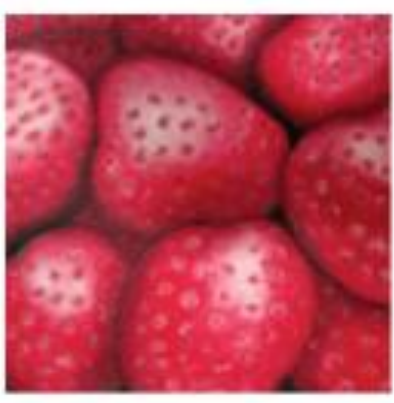

Sheer strawbery Lipitck on watercelor paver

Figure 4. Tight Crops and Abstraction

My sabbatical, which began with an art tour of Paris, Brussels and Amsterdam in the summer of 2012, greatly contributed to my development of this body of work. Seeing some of the famous original masterpieces, such as the Mona Lisa and a number of Vermeers, along with Rubens' and Rembrandt's houses, stimulated my thoughts about appropriations. The stained glass windows of Sainte Chapelle in Paris made me think about color and light. I began a daily journal to help me record and work through ideas for future pieces. In addition, I began attending a weekly critique group that inspired me to return to the medium of lipstick. As previously stated, the obvious resemblances of my work to Pop Art and especially to Warhol are undeniable; however, this was not a conscious decision but rather a realization after the fact as I attempt to contextualize my art into a historical framework.

As I continued to create additional pieces I not only explored the meanings implied by the use of the medium and working with appropriations but I also began to explore how color, texture, degrees of abstraction, and my use of repurposed or recycled material affect the meaning or perception of the work as well.

\section{Elements and Principles of Design}

With a background in visual design, I cannot help but experiment with how the design elements, such as color, texture, light and dark, as well as basic principles: contrast, repetition, unity, balance, and proportion are part of each composition I create. In the series of tulips pictured below (Figure 5), I experimented with the many shades of pink lipstick available and ask the viewer to consider how much of the tulip needs to be visible to recognize it as such. Also consider how when juxtaposed to the more formal tulips the abstract images are completely recognizable, but would they have been otherwise? 

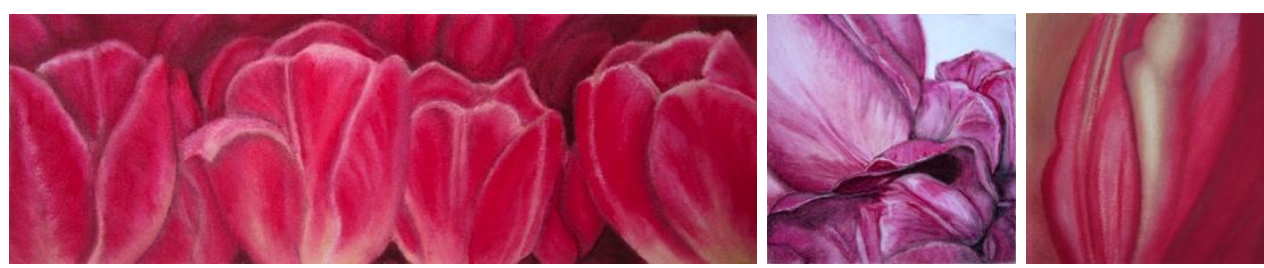

Figure 5. Exploring Different Shades, Crops, and Degrees of Abstraction

Fruits and flowers are ideal subject matter for lipstick since many are pink or red, plump and juicy, just like lips. To see if the medium of lipstick could be used to suggest something hard or papery and unrelated to anything we might call pretty, I experimented with the peppers, onions and lobsters (Figure 6).

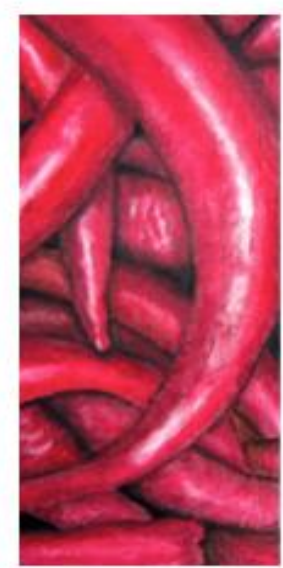

Red Hot Chili

Peppers

Lipstick on watercolor $14^{*} \times 6^{\prime \prime}$

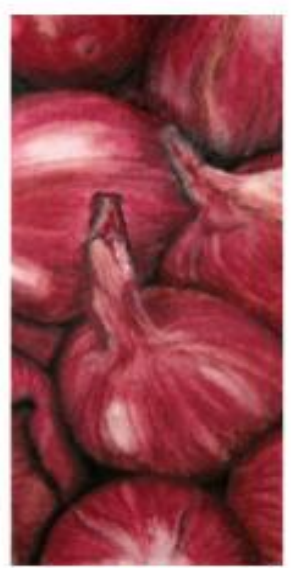

Layers of Beauty Lipstick on watercolo paper

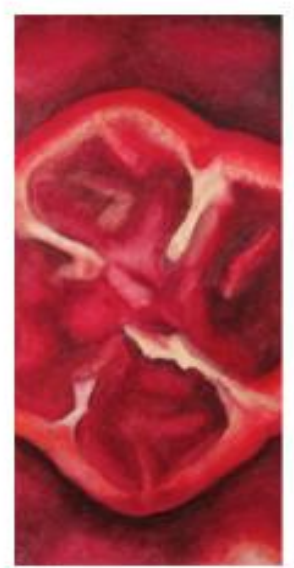

Inner Beauty Lipstick on watercolor paper

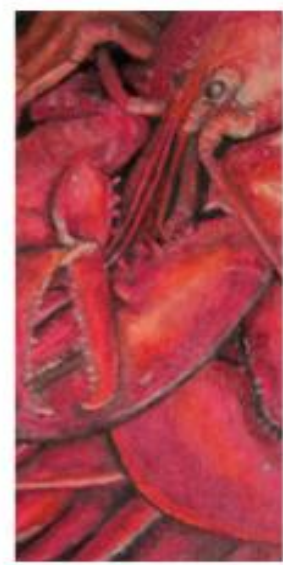

Lobsterweis. upstick on watercolor poper
$14^{\prime \prime} \times 6^{\prime \prime}$

Figure 6. Exploring Different Textures

My study of how color affects our concept of beauty continued with my appropriation of Marc Chagall's Red Nude Sitting Up, (Figure 7). I chose this piece because it was red and the mask-like face complements the medium, as lipstick masks our true appearance. I learned the value of using quality watercolor paper. I did not for this piece and the lipstick did not smudge well into the deep dimples of the paper. As a result the piece did not photograph well either. My interpretation came out much pinker and when viewed next to the original begs the question, "Does one color make the nude look more feminine or shocking than the other?" 


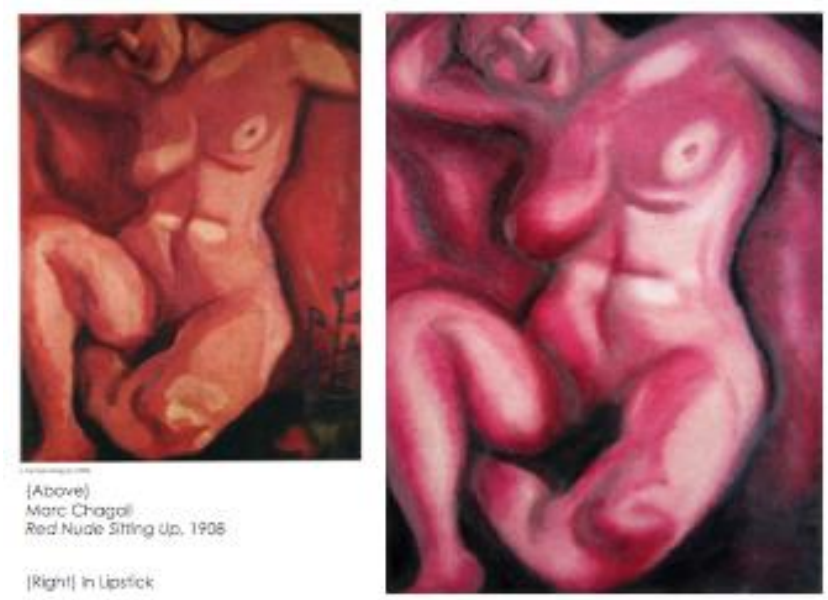

Figure 7. Color

\section{Impermanence}

I am often asked about the archival quality of my work. Just as beauty fades, so to shall my work. Numerous artists including Jackson Pollock and Mark Rothko have used nontraditional materials subject to decay in their most famous works creating a major challenge to conservators. While I take measures to preserve the work by first coating the watercolor paper with gesso and later spraying the finished piece with an oil-based fixative, the work will eventually change over time as do most things. Even Michelangelo's Sistine Chapel requires regular restoration. Much like an oil painting, the work seems to take a very long time to dry and I am not sure that it ever does entirely. Some of the colors in my original pieces have begun to turn into different hues. This further validates one of the ideas I am expressing with my art. The work will evolve over time and I am convinced that the most interesting exhibit will be when I show prints of the originals beside what has become of the original pieces years from now. I am experimenting with preserving some pieces under glass with space to breathe between the paper and the glass. I have exposed some pieces to extreme temperatures to see if I can get them to age more quickly. I painted decaying leaves from fall in New England with the intent that they will continue to decay in the lipstick image I captured on paper as they do in nature (Figure 8). Lipstick attempts to provide an image of preserved beauty. The medium of lipstick normally used to beautify is actually recycled, reused and repurposed. The irony is that I am using lipstick to create beauty and make a statement about beauty while simultaneously creating art from detritus and art that will eventually become detritus. "Museums enshroud objects with a sense of immortality. But nothing is timeless. We need to establish an acceptance of aging", states director Carol Mancusi-Ungaro of Harvard University Art Museums' Center for the 
Technical Study of Modern Art. ${ }^{14}$ As we admire the Parthenon for its antiquity, we see that there is beauty in the ruins and in its impermanence.
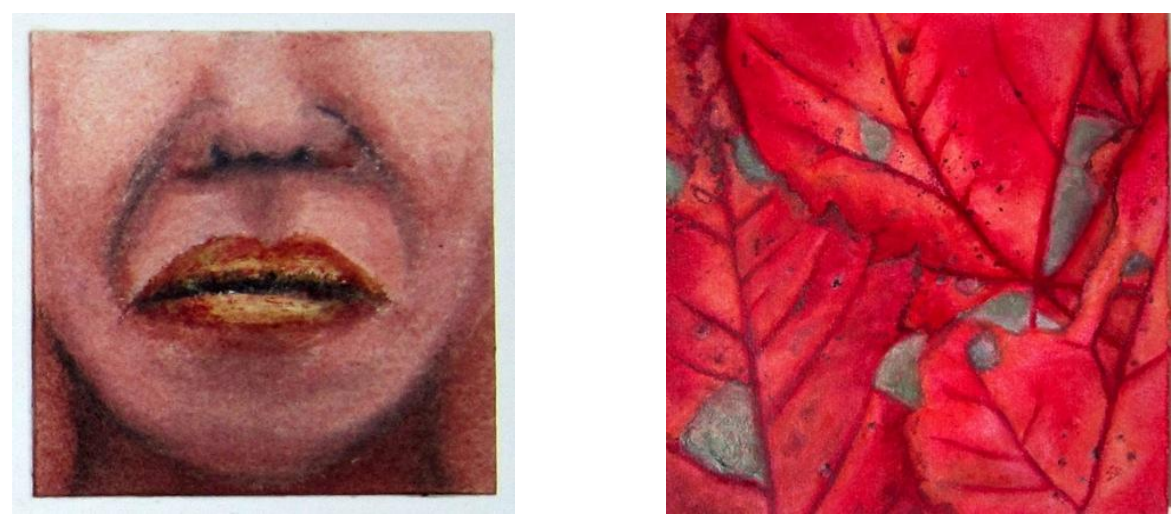

Figure 8. Impermanence

\section{Combining Mediums}

I was a bit of a purist initially keeping lipstick and eye makeup separate. I wanted to be able to say that I painted a work of art entirely in lipstick, a selfimposed restriction. At the urging of others, I have started to combine the makeup and lipstick to offer me a broader palette. Since both lipstick and eye makeup deal with the same issues of beauty, there is no significant implication to the meaning of the work. To create the piece, La Tour Eiffel à la Rouge à Lèvres (Figure 9), I actually worked in three mediums starting with the creation of a digital photo illustration, the combination of two photographs and the application of some special effects using Adobe Photoshop. Creating a derivative of my print, I used eye shadow and lipstick to create a sunset background and then added a lipstick and lip liner Eiffel Tower. The fabricated photo on which the image is based mimics the using makeup to transform natural appearance.

14. Catherine Dupree, "Impermanent Art," Harvard Magazine, 2002. 


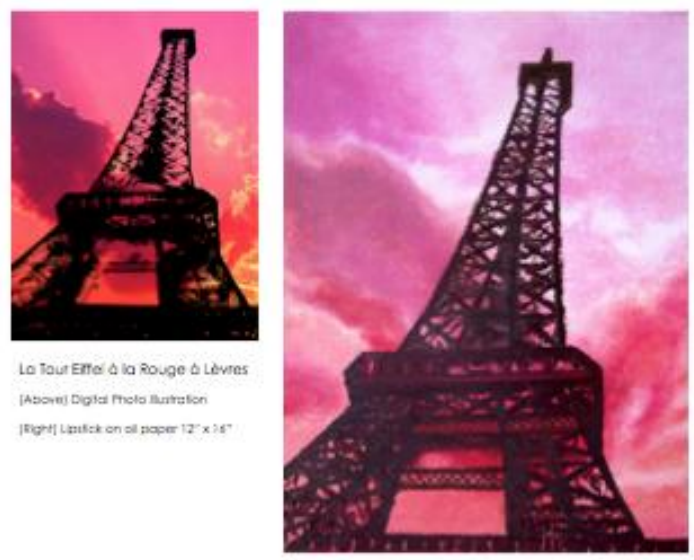

Figure 9. Combining Mediums

\section{The Competition}

My exploration of the medium would not be complete without an investigation into the competition. Three other "lipstick" artists, work primarily with pop culture subject matter. Natalie Irish (Irish) ${ }^{15}$ applies the lipstick to her lips then kisses large canvases repeatedly to apply the paint, producing large celebrity portraits. I do not have the lips for this application but I appreciate the exploration of the medium and the gesture of the kiss that contributes something different to her work. May Sum ${ }^{16}$ a Hong Kong-based makeup artist, sculpts the actual tip of lipstick in its tube, as well as other makeup, into pop culture icons. Makeup artist Laura Jenkinson ${ }^{17}$ uses the face as her canvas applying lipstick and paint to people's actual lips to make all sorts of popular cartoon characters. The expression on her live canvas affects the meaning of each piece. While we all have the use of lipstick as a medium in common, the work of these three artists differs greatly from my own work in terms of form, function and content.

More closely related to my style and intent, Sarah Britten ${ }^{18}$ has produced a series of still lifes using lipstick. Unlike my fruit and flower images, however, in which I fill the entire paper with image, Britten depicts a single fruit or flower, leaves the canvas surrounding her objects blank, and often

15. Natalie Irish, The art of kissing (blog), October 16, 2015, http://www.natalieirish.com.

16. Arabelle Sicardi, "You've never see makeup like this before," Refinery29, 2014, http://goo.gl/HNYLgW, (accessed October 16, 2015).

17. Dainius, "New cartoon lip art by Laura Jenkinson," Bored Panda, 2015, http://goo.gl/cwRRJa, (accessed October 16, 2015).

18. Sarah Britten, Sarah Britten Art (blog), October 16, 2015, http://www.sarahbrittenart.com. 
scratches into the lipstick markings. She notes on her website that "it's possible to write into the paint to reveal the white board beneath. This allows me to imbue the work with layers of meaning." She indicates that she hopes the viewer will see something different each time they view a piece of her work but does not elaborate on her intended meaning. While she focuses on layers of paint to offer the viewer a way to infer meaning, I focus attention by tightly cropping my subject matter and bleeding edges with the explicit intent of exploring concepts of beauty.

\section{Impact on Teaching Design}

The creation of my lipstick art has had a great impact on my teaching in the Communication Arts Department at Framingham State University (Framingham, MA, USA). My students are inspired and engaged by this example of creativity and fascinated by my use of lipstick as the medium. Participation in exhibitions has helped me to establish contacts for real life design projects to bring back to the classroom. I have become more open to creative exploration within my classroom.

\section{Future Directions}

The subject matter for future work is certainly unlimited. I have had suggestions to fill an entire gallery with makeup eyes and lipstick lips. There are plenty more fruits, vegetables and flowers I could recreate in pinks, reds, violets and oranges. I am also considering painting subject matter that would be unexpected in lipstick hues, such as things that we normally expect to see in greens and blues. Other appropriations and a full size lipstick Mona Lisa are on my list as well. My work would certainly be suited for cosmetic company advertisements and yet also may provide an opportunity to make important social statements.

As a cancer survivor, I have considered painting lipstick images of cancer cells to question if something so ugly can be made beautiful with makeup. This would deeply expand on the element of impermanence in my work as well.

I have begun experimenting with other related mediums such as nail polish, oil sticks and oil pastels. Each piece I complete directs the creation of the next piece. As impermanent as the medium and beauty, I allow the path of my work to evolve naturally based on the influences of my viewers and the other artwork to which I am exposed. 


\section{Acknowledgements}

My thanks to the Athens Institute for Education and Research for giving me the opportunity to present my artwork and creative process. I would also like to thank Framingham State University, my colleagues in the Communication Arts Department, friends and family, and especially my grandmother for her inspiring words of wisdom. Most importantly, thanks to my mom who is my idea person, my proofreader, my critic and my biggest supporter.

\section{Bibliography}

Bourgeois, Jean-Yves and Gallon, Vincent. "Lipstick: A Safe Bet." Premium Beauty News. 2009. http://goo.gl/csq4ge. Accessed October 16, 2015.

Burgard, Timothy. "Picasso and Appropriation." The Art Bulletin 73, no. 3 (1991).

Dainius. "New cartoon lip art by Laura Jenkinson." Bored Panda. 2015. http://goo.gl/cwRRJa. Accessed October 16, 2015.

Dupree, Catherine. "Impermanent Art." Harvard Magazine, 2002.

Eco, Umberto. On ugliness. New York: Rizzoli, 2007.

Leszkowicz, Pawel. "Sex and Subversion in the Art of the People's Republic of Poland." The Central European Journal of Social Sciences and Humanities 20 (2007): 51-85.

McLuhan, Marshall. Understanding Media: The Extensions of Man. New York: McGrawHill, 1964

O'Keeffe, Georgia. "I Can't Sing So I Paint." New York Sun, December 5, 1922, quoted in O'Keeffe, Stieglitz, and the Critics, 1916-1929, edited by Barbara Buhler Lynes. Chicago: Chicago University Press, 1991.

Ragas, Meg Cohen, Kozlowski, Karen and Vienne, Veronique. Read my lips. San Francisco: Chronicle Books [u.a.], 1998.

Sartwell, Crispin. "Beauty." In The Stanford Encyclopedia of Philosophy, edited by Edward N. Zalta. 2014. http://goo.gl/jvh9S3.

Sicardi, Arabella. "You've never see makeup like this before." Refinery29. 2014. http://goo.gl/HNYLgW. Accessed October 16, 2015.

Tanner, Jeremy. The invention of art history in Ancient Greece. Cambridge: Cambridge University Press, 2006.

Walter, Natasha. Living dolls. London: Virago, 2010.

Warhol, Andy. "Campbell's Soup Cans." Synthetic polymer paint, New York: Museum of Modern Art, 1962. 